\title{
A MODEL OF BEACH PROFILE EVOLUTION INCLUDING WAVE-UNDERTOW INTERACTION
}

\author{
Chi Zhang ${ }^{1}$, Jinhai Zheng ${ }^{2}$, Titi Sui ${ }^{3}$, Zeki Demirbilek ${ }^{4}$ and Lihwa Lin ${ }^{5}$
}

\begin{abstract}
A numerical model of beach profile evolution is developed to study the onshore and offshore sandbar migration under different wave conditions. The integrated model consists of wave model, roller model, flow model, sediment transport model and bed evolution model. In particular, the interaction between waves and wave-induced undertow current is considered in the flow model. This is achieved by adding a mean pressure gradient term into the firs-order momentum balance equation of flow. A simple empirical method is also introduced to describe the variation in eddy viscosity during one wave cycle. A preliminary application of the present model shows good agreements of both onshore and offshore sandbar migration phenomenon with the laboratory observation. It is found that the offshore sandbar migration is dominated by undertow while wave affects the transport rate. For the onshore sandbar migration, although sediment transport is mainly driven by wave and the undertow is weak, the transport pattern is considerably modified by undertow. It is shown that the combined effects of wave and undertow are important in beach profile evolution.
\end{abstract}

Keywords: beach profile evolution; sandbar; wave; undertow; numerical model

\section{INTRODUCTION}

Coastal beach profiles response actively to the imposed wave and current conditions. Understanding and modeling beach profile evolution under varying wave and current conditions is important in coastal engineering. Under energetic wave climate, the foreshore becomes flat and a sandbar is often observed in the offshore location. Under weak wave climate, the sandbar may move onshore and the foreshore becomes steep.

Sandbar is one of the most important geomorphic features in sandy coasts, as it serves a natural protection for beaches by inducing more energy dissipation of waves above it. The sandbar is quite dynamic. It can move onshore or offshore and grow or decay, depending on the site-specific hydrodynamic conditions and the time-scale of these processes. A large amount of research effort has been dedicated to the formation and migration of nearshore sandbars (e.g., Roelvink and Stive 1989; Gallagher et al. 1998; Hsu et al. 2006; Ruessink et al. 2007; Walstra et al. 2012). While the waveinduced undertow current moves sediment offshore and cause offshore sandbar migration under energetic waves (Gallagher et al. 1998), the skewness of nearshore wave velocities and accelerations drives onshore sediment transport and sandbar migration under moderate waves (Hoefel and Elgar 2003). In spite these mechanisms have been recognized and successfully implemented in various models to simulate onshore or offshore sandbar migration, simulating both conditions together with a general model setting is still a challenging problem (Van Rijn et al. 2003; Ruessink et al. 2007). This may partially be explained by some missing or not well described processes in the models. Recent studies have investigated the relationship between breaking turbulence and sediment concentration and its implication to undertow-driven sediment transport (Aagaard and Hughes 2010; Grasso et al. 2012). However, the interaction between the high-frequency wave motion and the low-frequency undertow and their combined effects on sediment transport are still not well understood yet.

This paper presents the development of a numerical model of beach profile evolution in which the wave-undertow interaction are considered. The model was tested with the onshore and offshore sandbar migration experiments. The distinct features of these two processes and the effects of waveundertow interaction are discussed.

${ }^{1}$ State Key Laboratory of Hydrology-Water Resources and Hydraulic Engineering, Hohai University, 1 Xikang Road, Nanjing, 210098, China

${ }^{2}$ State Key Laboratory of Hydrology-Water Resources and Hydraulic Engineering, Hohai University, 1 Xikang Road, Nanjing, 210098, China

${ }^{3}$ State Key Laboratory of Hydrology-Water Resources and Hydraulic Engineering, Hohai University, 1 Xikang Road, Nanjing, 210098, China

${ }^{4}$ U.S. Army Engineer Research and Development Center, Coastal and Hydraulics Laboratory, 3909 Halls Ferry Road, Vicksburg MS, 39180, USA

${ }^{5}$ U.S. Army Engineer Research and Development Center, Coastal and Hydraulics Laboratory, 3909 Halls Ferry Road, Vicksburg MS, 39180, USA 


\section{MODEL DESCRIPTION}

\section{Wave Model}

Wave characteristics are calculated using the wave-energy balance equation:

$$
\frac{\partial\left(E_{w} c_{g}\right)}{\partial x}=-D_{w}
$$

where $E_{\mathrm{w}}$ is wave energy, $c_{\mathrm{g}}$ is group velocity, $D_{\mathrm{w}}$ is the energy dissipation due to breaking and is calculated according to Battjes and Janssen (1978), as modified by Janssen and Battjes (2007).

\section{Roller Model}

The roller energy is computed by (Stive and De Vriend 1994)

$$
\begin{gathered}
\frac{\partial\left(2 E_{r} c\right)}{\partial x}=D_{w}-D_{r} \\
D_{r}=\frac{2 g E_{r} \sin \beta}{c}
\end{gathered}
$$

where $E_{\mathrm{r}}$ is roller energy, $c$ is phase velocity, $D_{\mathrm{r}}$ is roller dissipation, $g$ is gravitational acceleration and $\beta=0.1$ is the roller slope. The wave set-up $\bar{\eta}$ is estimated with the depth-integrated and time-averaged momentum equation including roller effects:

$$
\frac{\partial S_{x x}}{\partial x}+\frac{\partial 2 E_{r}}{\partial x}+\rho g(h+\bar{\eta}) \frac{\partial \bar{\eta}}{\partial x}=0
$$

where $S_{x x}$ is wave radiation stress, $\rho$ is water density, $h$ is the still water depth.

\section{Flow Model}

The intra-wave flow velocity is modeled based on the first-order momentum equation, written as

$$
\frac{\partial u}{\partial t}=\frac{\partial u_{\infty}}{\partial t}+\frac{\partial}{\partial z}\left[\left(v_{t}+v\right) \frac{\partial u}{\partial z}\right]-\frac{1}{\rho} \frac{\partial \bar{p}}{\partial x}-\frac{1}{\rho} \frac{\partial \bar{\tau}_{\mathrm{bls}}}{\partial z}
$$

where $u$ is the instantaneous flow velocity, $u_{\infty}$ is the wave-induced free stream velocity, $v_{\mathrm{t}}$ and $v$ are turbulent and kinematic eddy viscosity, respectively, $\bar{p}$ is the mean pressure, $D_{\mathrm{f}}$ is the energy dissipation in the bottom boundary layer, $\bar{\tau}_{\text {bls }}$ is the additional mean shear stress induced by the boundary layer streaming. The first term in the right side of Eq. (5) represents wave-induced pressure gradient. The third term represents the mean horizontal pressure gradient related to undertow (Zhang et al. 2011). The fourth term is restricted in the bottom boundary layer and is expressed as (Reniers et al. 2004)

$$
-\frac{1}{\rho} \frac{\partial \bar{\tau}_{\mathrm{bls}}}{\partial z}= \begin{cases}\frac{D_{f}}{\rho c \delta} & (z \leq \delta) \\ 0 & (z>\delta)\end{cases}
$$

where $\delta$ is the boundary layer thickness.

The time-averaged and depth-averaged turbulent eddy viscosity $v_{\mathrm{tm}}$ is determined according to Battjes (1975):

$$
v_{\mathrm{tm}}=f_{\mathrm{v}} H_{\mathrm{rms}}\left(\frac{D_{\mathrm{r}}}{\rho}\right)^{1 / 3}
$$

where $f_{v}$ is a constant taken as $0.025, H_{\mathrm{rms}}$ is the root mean square wave height, $h_{\mathrm{t}}$ is the elevation of wave trough level from the bed.

In this study, we assume that the eddy viscosity is linearly distributed over the depth and is timedependent during one wave cycle: 


$$
\begin{gathered}
v_{\mathrm{t}}=2 v_{\mathrm{tm}} \frac{z}{h_{\mathrm{t}}} \frac{\left|u_{*}^{3}\right|}{\overline{\left|u_{*}^{3}\right|}} \\
u_{*}=\cos \varphi u_{\infty}+\sin \varphi \frac{1}{\omega} \frac{d u_{\infty}}{d t}
\end{gathered}
$$

where $u_{*}$ is defined as the equivalent velocity for turbulence generation and is related to the instantaneous value and acceleration of free streaming velocity and a phase shift angle $(\varphi) . u_{*}$ has the same form to the bed shear stress parameterization of Nielsen and Callaghan (2003) but with different physical meaning. In this study, $\varphi$ is calibrated to be $26^{\circ}$, which is different from the value proposed by Nielsen and Callaghan (2003). This can be explained by the fact that in the present formulation $\varphi$ not only describes the phase difference between free steaming and the bed-generated turbulence but also takes the breaking-generated turbulence into account. It has been found that the model results are sensitive to the value of $\varphi$. Time series of the free stream velocity is computed with the functions of Elfrink et al. (2006).

At each cross-shore location, the mean horizontal pressure gradient $(-1 / \rho \partial \bar{P} / \partial x)$ in Eq. (5) is not known at first. This term is not directly estimated. Instead, it is automatically obtained using an iterative algorithm which forces the undertow flux to satisfy the time-averaged mass continuity equation:

$$
\frac{1}{T} \int_{0}^{T} \int_{0}^{h_{\mathrm{t}}} u d z d t+\frac{E_{\mathrm{w}}}{\rho c}+\frac{2 E_{\mathrm{r}}}{\rho c}=0
$$

where $T$ is wave period. At the bottom boundary, the no-slip condition for velocity is used. At the wave trough level, the shear stress formula of Deigaard et al. (1993) is employed.

\section{Sediment Transport Model}

The time-dependent sediment concentration and sediment flux are calculated with the sediment advection-diffusion equation:

$$
\frac{\partial c}{\partial t}=w_{\mathrm{s}} \frac{\partial c}{\partial z}+\frac{\partial}{\partial z}\left(\varepsilon_{\mathrm{s}} \frac{\partial c}{\partial z}\right)
$$

where $c$ is sediment concentration, $w_{\mathrm{s}}$ is the settling velocity of suspended sediment, $\varepsilon_{\mathrm{s}}$ is the sediment diffusivity, which is equal to $v_{\mathrm{t}}$. The pick-up function is used as the bottom boundary condition and the zero-flux condition is used at the top.

For bedload transport, a Meyer-Peter Mueller formula (Ribberink et al. 1998) is used that functions the instantaneous bedload transport rate with the Shields parameter $(\theta)$ :

$$
q_{\mathrm{b}}=11 \frac{\theta}{|\theta|}(|\theta|-0.05)^{1.65} \sqrt{(s-1) g d_{50}^{3}}
$$

where $q_{\mathrm{b}}$ is the bedload transport rate, $s$ is the density ratio between sediment and water $(\mathrm{s}=2.65), d_{50}$ is the median grain diameter of sediment.

The time-averaged net sediment transport rate can be calculated by

$$
q=\int_{0}^{T}\left(q_{\mathrm{b}}+\int u c d z\right) d t
$$

where $q$ is the total net sediment transport rate.

\section{Sediment Transport Model}

The bed evolution is computed by the sediment mass balance equation:

$$
\frac{\partial z_{\mathrm{b}}}{\partial t}=-\frac{1}{1-p} \frac{\partial q}{\partial x}
$$

where $z_{\mathrm{b}}$ is bed elevation, $p=0.3$ is bed porosity. 


\section{RESULTS AND DISCUSSION}

A preliminary application is shown to investigate the model's overall skills for simulating both the onshore and offshore sandbar migration in a laboratory experiment (Maddux et al. 2006; Guannel et al. 2007). In the experiment, the sandbar was firstly moved offshore during 3.5 hours of energetic waves with larger heights and shorter period, followed by an onshore migration of 11.25 hours under actions of weak waves with smaller heights and longer period, see Figure 1 for details.

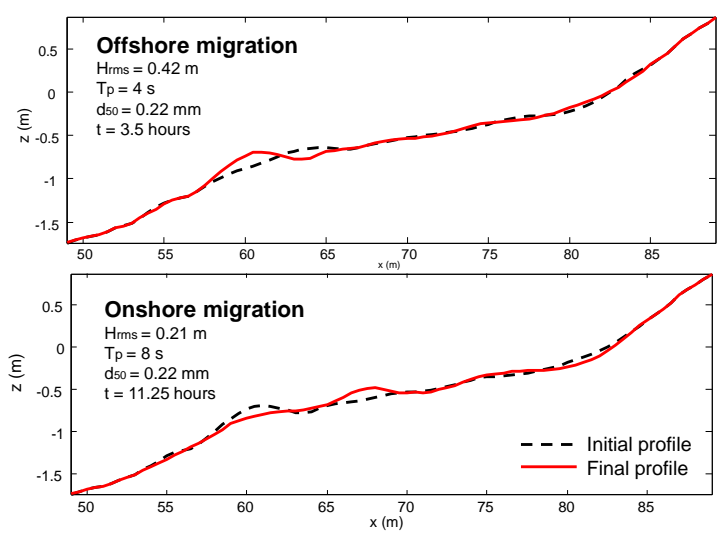

Figure 1. Experimental set-up.

Figure 2 shows the comparisons of wave height, mean water level and undertow velocity for both cases. The computed results agree well with the measured data. It is found that the undertow velocity during offshore migration is underestimated near the bar crest. However, for the onshore migration, the cross-shore distribution of undertow velocity is well reproduced. The undertow is considerably weaker during onshore migration than offshore migration.

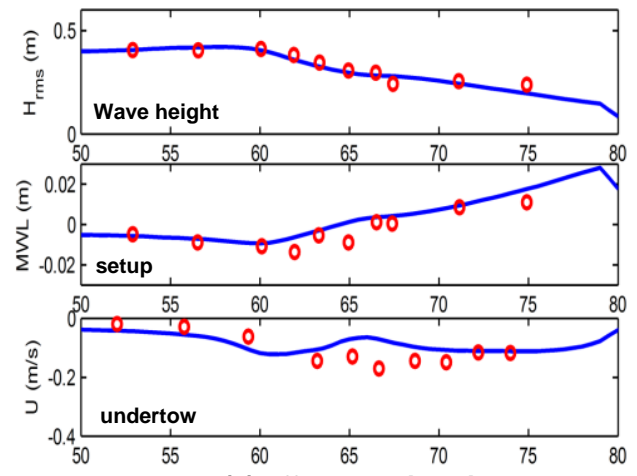

(a) offshore migration

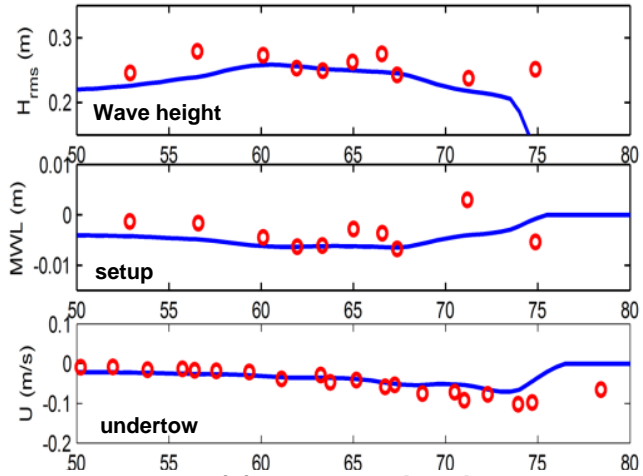

(b) onshore migration

Figure 2. Comparisons of wave height, set up and undertow between prediction (continuous lines) and observation (circles).

Figure 3 shows the comparisons of transport rates and beach profile evolution for both cases. The calculated sediment transport rate shows a consistent trend of cross-shore variation with the measurements. It is found that for both cases, bedload dominates the transport processes and the maximum transport rate occurs near the bar crest. After calibration, the model reasonably reproduces the distinct features of on-offshore sediment transport processes and the observed sandbar migration under different wave and undertow conditions, implying that the present model setting captures the major physical mechanisms in these two cases.

The effects of wave-undertow interaction are illustrated in Figure 4 and Figure 5. For comparison, wave-induced free stream velocity is set to zero in the model to consider undertow only. Undertow is neglected by eliminating the second and third terms in the left side of Eq. (10). It is shown in Figure 4 that waves affect the quantity and the local gradient of the offshore directed transport rate. In particular, waves enhance the offshore transport and produces greater gradients of transport rate near the bar crest which is consistent with the observation. This may arise from both the enhanced intra-wave near-bed velocity and thus the enhanced bed shear stress. For the case of onshore migration, Figure 5 shows that 
although the weak undertow can hardly move sand itself, it does considerably modifies the waveinduced transport pattern. If undertow is neglected in this case, the model will significantly overpredict the onshore transport rate and fail to capture the location of maximum transport rate. It is summarized that the combined influence of wave and undertow on sediment transport is not a simple summation of the individual effects, but is rather a result of the complex wave-undertow interaction.
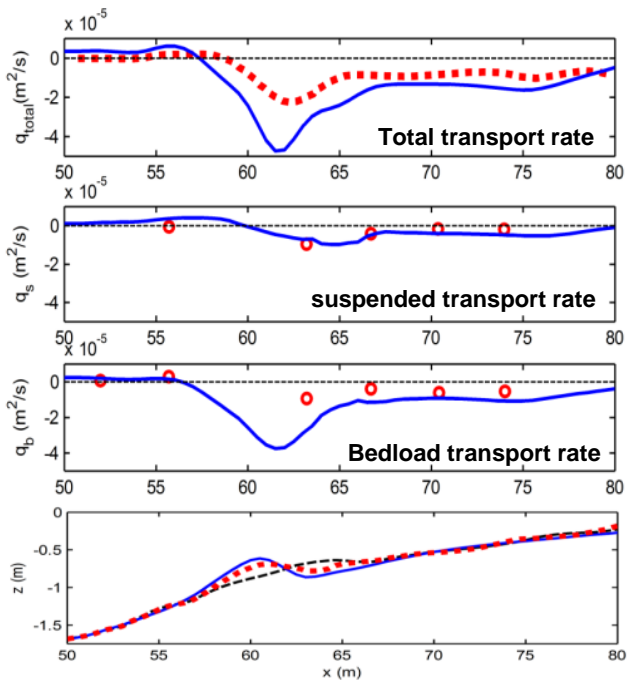

(a) offshore migration
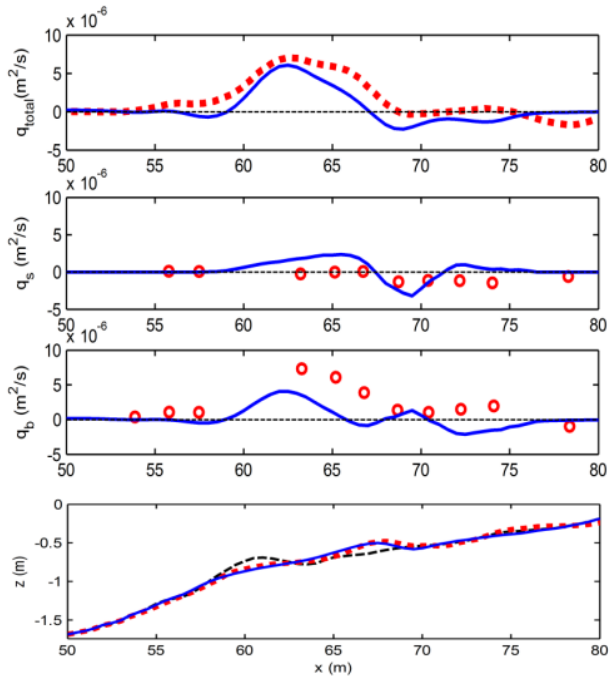

(b) onshore migration

Figure 3. Comparisons of transport rates and beach profile evolution between prediction (continuous lines) and observation (circles and dot lines).

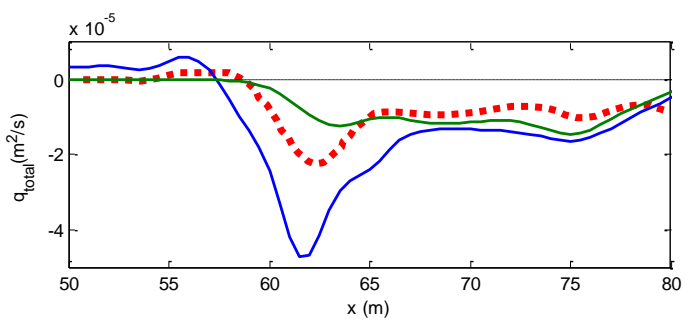

Figure 4. Comparisons of net transport rate including wave-undertow interaction (blue line) and undertow only (green line) for the case of offshore migration. The measured transport rate is plotted with red dot line.

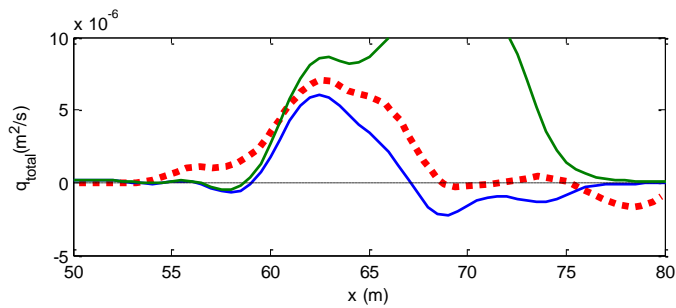

Figure 5. Comparisons of net transport rate including wave-undertow interaction (blue line) and wave only (green line) for the case of onshore migration. The measured transport rate is plotted with red dot line.

\section{CONCLUSION}

A model of beach profile evolution is developed, in which the wave-undertow interaction is included. The model well reproduces the observed trend of on-offshore sandbar migration beneath different incident wave conditions. It is shown that wave-undertow interaction plays a significant role in beach profile evolution. The combined influence of wave and undertow on sediment transport is not a simple summation of the individual effects. In the present case, the offshore sandbar migration is dominated by undertow while wave affects the transport rate. For the onshore sandbar migration, 
although sediment transport is mainly driven by wave and the weak undertow can hardly move sand itself, the transport pattern is considerably modified by undertow.

\section{ACKNOWLEDGMENTS}

The work was supported by the National Natural Science Foundation of China (51209082), the National Key Basic Research Development Program "973 project" of China (2010CB429002), the National Key Technology Research and Development Program (2012BAB03B01), the 111 project (B12032) and the Special Research Funding of State Key Laboratory of Hydrology-Water Resources and Hydraulic Engineering (2009585812).

\section{REFERENCES}

Aagaard, T., and M.G. Hughes, 2010. Breaker turbulence and sediment suspension in the surf zone, Marine Geology, 271, 250-259.

Battjes, J.A., 1975. Modelling of turbulence in the surf zone, Proceedings Symposium on Modeling Techniques, ASCE, 1050-1061.

Battjes, J.A., and J.P.F.M. Janssen. 1978. Energy loss and set-up due to breaking of random waves, Proceedings of $14^{\text {th }}$ International Conference on Coastal Engineering, ASCE, 569-587.

Deigaard, R., 1993. A note on the three dimensional shear stress distribution in a surf zone, Coastal Engineering, 20, 157-171.

Elfrink, B., D.M. Hanes, and B.G. Ruessink, 2006. Parameterization and simulation of near bed orbital velocities under irregular waves in shallow water, Coastal Engineering, 53, 915-927.

Gallagher, E.L., S. Elgar, and R.T. Guza, 1998. Observations of sandbar evolution on a natural beach, Journal of Geophysical Research, 103, 3203-3215.

Grasso, F., B. Castelle, and B.G., Ruessink, 2012. Turbulence dissipation under breaking waves and bores in a natural surf zone, Continental Shelf Research, 43, 133-141.

Guannel, G., H.T. Ozkan-Haller, M.C. Haller, and J.T. Kirby, 2007. Influence of velocity moments on sand bar movement during CROSSTEX, Proceedings of the $6^{\text {th }}$ International Symposium on Coastal Engineering and Science of Coastal Sediment Process, ASCE, 28-41.

Hoefel, F., and S. Elgar, 2003. Wave-induced sediment transport and sandbar migration, Science, 299, 1885-1887.

Hsu, T.J., S. Elgar, and R.T. Guza, 2006. Wave-induced sediment transport and onshore sandbar migration, Coastal Engineering, 53, 817-824.

Janssen, T.T., and J.A. Battjes, 2007. A note on wave energy dissipation over steep beaches, Coastal Engineering, 54, 711-716.

Maddux, T.B., E.A. Cowen, D.L. Foster, M.C. Haller, and T.P. Stanton, 2006. The Cross Shore sediment transport experiment (CROSSTEX), Proceedings of $14^{\text {th }}$ International Conference on Coastal Engineering, ASCE, 2547-2559.

Nielsen, P., and D.P. Callaghan, 2003. Shear stress and sediment transport calculations for sheet flow under waves, Coastal Engineering, 47, 347-354.

Reniers, A.J.H.M., E.B. Thomton, T.P. Stanton, and J.A. Roevink, 2004. Veritcal flow structure during Sandy Duck: observations and modeling, Coastal Engineering, 51, 237-260.

Ribberink J.S., 1998. Bedload transport for steady flows and unsteady oscillatory flows, Coastal Engineering, 34, 59-82.

Roelvink, J. A., and M.J.F. Stive, 1989. Bar-generating cross-shore flow mechanisms on a beach, Journal of Geophysical Research, 94, 4785-4800.

Ruessink, B.G., Y. Kuriyama, A.J.H.M. Reniers, J.A. Roevink, and D.J.R. Walstra, 2007. Modeling cross-shore sandbar behavior on the timescale of weeks, Journal of Geophysical Research, 112, doi: 10.1029/2006JF000730.

Stive, M.J.F., and H.J. De Vriend. 1994. Shear stresses and mean flow in shoaling and breaking waves, Proceedings of $24^{\text {th }}$ International Conference on Coastal Engineering, ASCE, 594-608.

van Rijn, L.C, D.J.R. Walstra, B. Grasmeijer, J. Sutherland, S. Pan, and J.P. Sierra, 2003. The predictability of cross-shore bed evolution of sandy beaches at the time scales of storms and seasons using process-based profile models, Coastal Engineering, 47, 295-327.

Walstra, D.J.R., A.J.H.M. Reniers, R. Ranasinghe, J.A. Roelvink, and B.G., Ruessink, 2012. On bar growth and decay during interannual net offshore migration, Coastal Engineering, 60, 190-200.

Zhang, C., Zheng, J., Wang, Y., and Z. Demirbilek, 2011. Modeling wave-current bottom boundary layers beneath shoaling and breaking waves, Geo-Marine letters, 31, 189-201. 